\title{
Measurements of sinus impulse conduction from electrogram of bundle of His
}

\author{
S. Bekheit ${ }^{1}$, J. G. Murtagh, P. Morton, and E. Fletcher \\ From the Cardiovascular Unit, Belfast City Hospital
}

A catheter technique for recording bundle of His activity is described. The method is simple and the electrode catheter can be introduced percutaneously into the femoral vein by the Seldinger technique.

Measurements of sinus impulse conduction were made in 20 patients from the bundle of His electrogram. Slight variation in the PR interval of the standard electrocardiogram occurred, but the HV interval of the electrogram remained constant. It is concluded that in normal sinus conduction changes in the PR interval always take place above the bundle of His.

An important catheter technique for systematic recording of His bundle activity in man has been described by Scherlag et al. (1969). These authors successfully recorded a His bundle electrogram in 9 out of 10 patients studied. The technique has been employed in a study of heart block by Damato et al. (1969) and the His bundle deflection has been authenticated by pervenous pacing of the specialized conducting system in man (Scherlag, Kosowsky, and Damato, 1967; Scherlag et al., 1969; Narula, Scherlag, and Samet, 1970b). Thus, the conduction of impulses both normal and abnormal can be more precisely studied under clinical conditions by methods hitherto confined to the experimental animal (Scherlag et al., 1967). The current interest in cardiac arrhythmias, especially in relation to coronary heart disease, and indications for artificial pacemakers, make an understanding of their fundamental mechanisms of practical importance as well as of physiological interest. The His bundle electrogram records the electrical activity of the specialized conducting tissues. New nomenclature of deflections and time intervals is required, and in this paper the terminology used by Scherlag 'et al. (1969) is employed.

\section{Patients and methods}

Twenty patients were studied, 16 men and 4 women, whose ages ranged from 39 to 75 years. All were in sinus rhythm. Four patients were

Received 3 December 1970.

${ }^{1}$ Research Fellow, Northern Ireland Hospitals Authority. Investigations supported by a Grant from Medical Education and Research Committee, Northern Ireland Hospitals Authority. being treated with digoxin and one of these was also receiving procainamide. Most of these cases were studied under no sedation, but a few were given sodium amytal $100 \mathrm{mg}$ intramuscularly one hour before the procedure.

A bipolar electrode catheter (USCI) with $2 \mathrm{~mm}$ electrodes, I cm apart, was introduced via the right saphenous vein, or the right femoral vein using the Seldinger technique. It was advanced under fluoroscopy control so that its distal curve arched across the tricuspid valve with its tip in the right ventricle (Fig. I). The terminals were connected to a high gain AC input preamplifier (Sanborn Model 350-2700). The distal tips of the catheter were gently moved to and fro across the tricuspid ring until a bundle of His deflection was clearly seen between the atrial and ventricular electrogram on the oscilloscope. On a second channel a simultaneous standard limb lead II electrocardiogram was recorded. The activity of the bundle of His was obtained at a cut-off frequency of I5-I500 cycles/sec, and recorded at a paper speed of $100 \mathrm{~mm} / \mathrm{sec}$.

A typical bundle of His electrogram is shown in Fig. 2. This illustrates that the $P R$ interval of the surface electrocardiogram represents the delay in transmission of a sinus impulse in the atrium, AV node, and between the bundle of $H$ is and the ventricles. The PA interval represents intra-atrial conduction time and was measured between the onset of the $\mathbf{P}$ wave of the standard electrocardiogram and the onset of the rapid deflection of the atrial electrogram. The $\mathrm{AH}$ interval was measured from the onset of the rapid deflection of the atrial electrogram to the beginning of the rapid deflection of the bundle of His, and represents the conduction time in the AV node (Narula et al., r970a, b; Hoffman et al., 1963). The HV interval was measured from the onset of the rapid deflection of the bundle of $\mathrm{His}$ to the onset of ventricular septal activation. HS is the interval between the onset of the rapid deflection of the bundle of His 
TABLE Time intervals in msec calculated from standard limb lead II electrocardiograms and bundle of His electrograms in 20 patients with normal sinus conduction

\begin{tabular}{|c|c|c|c|c|c|c|c|}
\hline Case No. & Age & $\operatorname{Sex}$ & Diagnosis and treatment & $V V(m s e c)$ & & $P R$ (msec) & \\
\hline $\mathbf{I}$ & 39 & $\mathbf{F}$ & Normal heart & $675-735$ & $(706 \pm 18)$ & $130-145$ & $(137 \pm 4)$ \\
\hline 2 & 69 & $\mathbf{M}$ & Sinus bradycardia and sinus arrhythmia & $1365-2155$ & $(1840 \pm 279)$ & $115-125$ & $(121 \pm 2 \cdot 6)$ \\
\hline 3 & 47 & F & Normal heart & $730-780$ & $(744 \pm 16)$ & $150-160$ & $(154 \pm 2 \cdot 5)$ \\
\hline 4 & 50 & $\mathbf{M}$ & Chest pain ? cause & $1015-1050$ & $(1035 \pm 13)$ & I70-I75 & $(172 \pm 2 \cdot 4)$ \\
\hline 5 & 49 & $\mathbf{M}$ & Normal heart & 910-1010 & $(942 \pm 26)$ & $150-160$ & $(155 \pm 2 \cdot 8)$ \\
\hline 6 & 46 & $\mathrm{~F}$ & Auscultatory signs of mitral stenosis & $660-685$ & $(675 \pm 6)$ & $185-190$ & $(187 \pm 2.5)$ \\
\hline 7 & 43 & $\mathbf{M}$ & Normal heart & $1060-1140$ & $(1093 \pm 22)$ & $150-170$ & $(162 \pm 5 \cdot 2)$ \\
\hline 8 & $6 I$ & $\mathrm{~F}$ & Normal heart & $590-740$ & $(668 \pm 34)$ & $155-165$ & $(160 \pm 5)$ \\
\hline 9 & 67 & M & Normal heart & $840-935$ & $(908 \pm 27)$ & $150-165$ & $\left(15^{8} \pm 6\right)$ \\
\hline 10 & 57 & $\mathbf{M}$ & Ischaemic heart disease & $740-790$ & $(763 \pm 17)$ & $150-165$ & $(157 \pm 6)$ \\
\hline I I & 60 & $\mathbf{M}$ & Ischaemic heart disease : digoxin, $0.5 \mathrm{mg} / \mathrm{dy}$ & $820-880$ & $(854 \pm 18)$ & $140-145$ & $(I 4 I \pm 4)$ \\
\hline 12 & 60 & $\mathbf{M}$ & Ischaemic heart disease & $1120-1315$ & （I I57 士53） & $125-140$ & $(133 \pm 4 \cdot 5)$ \\
\hline I3 & 75 & $\mathbf{M}$ & $\begin{array}{l}\text { Ischaemic heart disease: digoxin, } 0.5 \mathrm{mg} / \mathrm{dy} \\
\text { procainamide, I } \mathrm{g} / \mathrm{dy}\end{array}$ & $790-850$ & $(820 \pm 18)$ & $170-180$ & $(174 \pm 3.5)$ \\
\hline 14 & 55 & $\mathbf{M}$ & Ischaemic heart disease: digoxin, $0.5 \mathrm{mg} / \mathrm{dy}$ & $730-805$ & $(773 \pm 29)$ & $155-165$ & $(I 6 I \pm 4)$ \\
\hline I5 & 52 & $\mathbf{M}$ & Ischaemic heart disease: digoxin, $0.5 \mathrm{mg} / \mathrm{dy}$ & $870-900$ & $(889 \pm 8)$ & $140-155$ & $(148 \pm 4)$ \\
\hline 16 & 50 & $\mathbf{M}$ & Ischaemic heart disease & I0I0-I095 & $(1055 \pm 21)$ & $120-135$ & $(129 \pm 3 \cdot 7)$ \\
\hline 17 & 68 & $\mathbf{M}$ & Ischaemic heart disease & $1045^{-1}$ I 80 & $($ I $127 \pm 38)$ & $145-155$ & (I53 \pm 3.5$)$ \\
\hline I8 & 52 & $\mathbf{M}$ & Ischaemic heart disease & $850-905$ & $(884 \pm 13)$ & $165-180$ & $(I 70 \pm 4)$ \\
\hline 19 & 60 & $M$ & Ischaemic heart disease & $850-920$ & $(891 \pm 24)$ & $160-170$ & $(162 \pm 3 \cdot 2)$ \\
\hline 20 & 59 & $M$ & Ischaemic heart disease & I0I5-1065 & $(1033 \pm 16)$ & $140-150$ & $(144 \pm 3.5)$ \\
\hline
\end{tabular}

to the end of the $S$ wave of the QRS complex of the electrocardiograms, and represents the total intraventricular conduction time. The rate of ventricular discharge (VV) was calculated by measuring the interval between the onset of two consecutive ventricular electrograms.

In every patient each of these measurements was calculated in at least ro different cycles and the results are summarized in the Table.

\section{Results}

The HV interval for this series ranged between $35-45 \mathrm{msec}$ but was invariably constant for each patient. The AH interval in this group measured between $50-125 \mathrm{msec}$ and varied slightly in each patient (mean standard deviation 2.6). The PA interval in the whole group ranged from ro-50 msec and there was slight variation in each patient (mean standard deviation 3.4). The HS interval for all the patients ranged from $120-145 \mathrm{msec}$, and was relatively constant (mean standard deviation I.4). These measurements are in agreement with the observations reported by Narula et al. (1968), Narula et al. (1970a), and Scherlag et al. (1969).

In this study, the bundle of His was considered to be the origin of the $\mathrm{BH}$ deflection only when it fulfilled the criteria suggested by

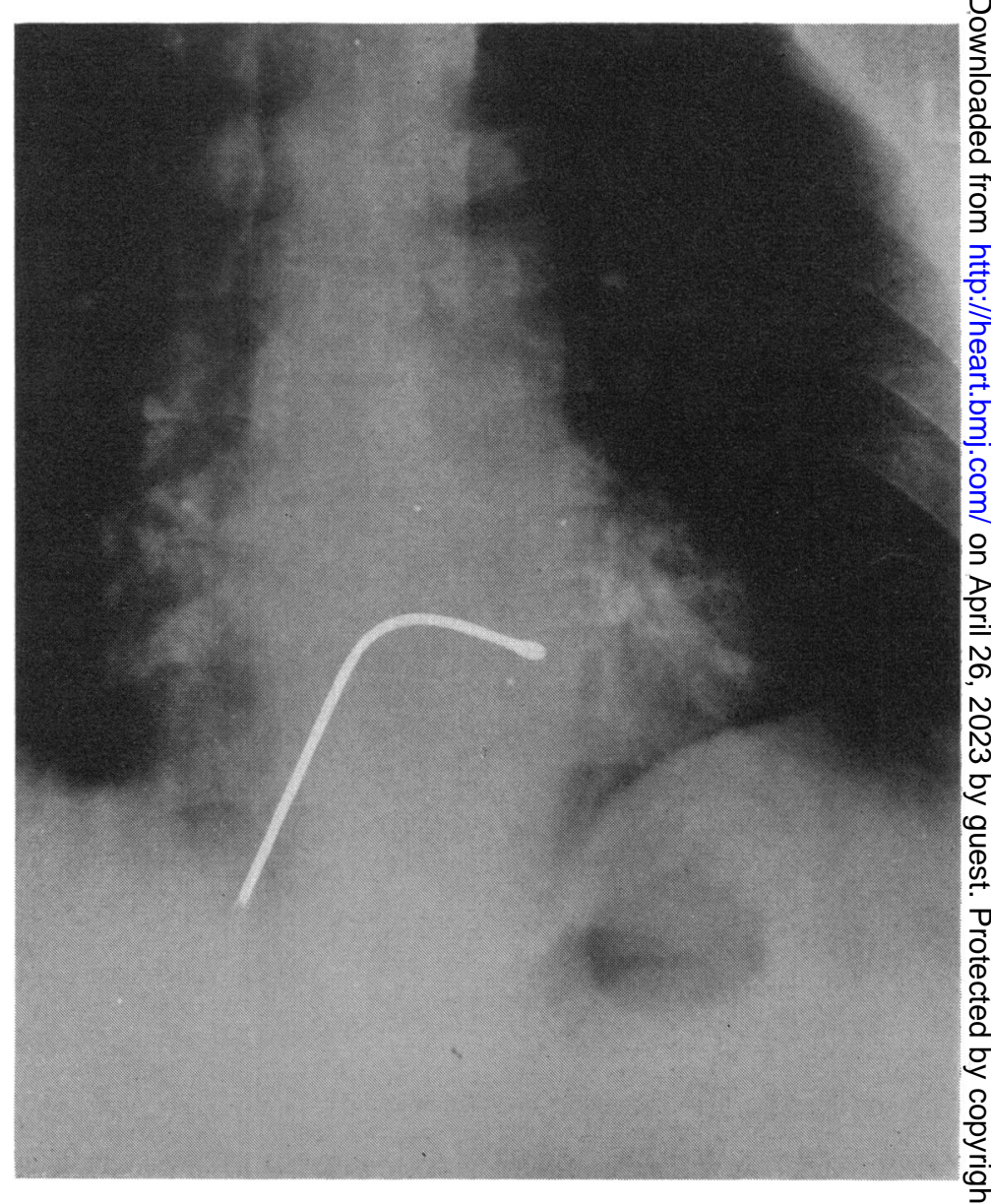

FIG. I The electrode catheter (touched up) in position for recording the bundle of His electrogram. 


\begin{tabular}{|c|c|c|c|c|c|c|}
\hline \multicolumn{2}{|c|}{$P A(m s e c)$} & \multicolumn{2}{|c|}{$A H$ (msec) } & $H V$ (msec) & \multicolumn{2}{|c|}{$H S$ (msec) } \\
\hline $30-40$ & $\left(3^{8} \pm 3 \cdot 3\right)$ & $60-70$ & $(64 \pm 2 \cdot I)$ & $35(-)$ & $120-130$ & $(124 \pm 4 \cdot 5)$ \\
\hline $10-15$ & $(11 \pm 2)$ & $60-65$ & $(61 \pm 2)$ & $45 \quad(-)$ & $130-140$ & $(136 \pm 3)$ \\
\hline $50-55$ & $(5 I \pm I \cdot 6)$ & $60-65$ & $(61 \pm 2)$ & $40 \quad(-)$ & $140-150$ & $(145 \pm 5)$ \\
\hline $35-45$ & $(42 \pm 4)$ & $85-90$ & $(86 \pm 2)$ & $45 \quad(-)$ & 120 & $(-)$ \\
\hline $40-50$ & $(46 \pm 3 \cdot 7)$ & $60-70$ & $(64 \pm 5 \cdot 4)$ & $45 \quad(-)$ & 120 & $(-)$ \\
\hline $30-35$ & $(31 \pm 1 \cdot 5)$ & $120-125$ & $(122 \pm 2 \cdot 5)$ & $35(-)$ & 120 & $(-)$ \\
\hline $40-50$ & $(48 \pm 3 \cdot 4)$ & $75-90$ & $(83 \pm 4)$ & $35(-)$ & $120-130$ & $(124 \pm 5)$ \\
\hline $45-55$ & $(50 \pm 5)$ & $65-70$ & $(66 \pm 6)$ & $45 \quad(-)$ & 135 & $(-)$ \\
\hline $30-45$ & $(36 \pm 5)$ & $80-85$ & $(83 \pm 1 \cdot 5)$ & $40 \quad(-)$ & $130-135$ & $(132 \pm 2)$ \\
\hline $35-45$ & $(39 \pm 4)$ & $80-85$ & $(81 \pm 2)$ & $35(-)$ & 135 & $(-)$ \\
\hline $40-45$ & $(44 \pm \mathrm{r} \cdot 3)$ & $60-65$ & $(62 \pm 2 \cdot 5)$ & $35(-)$ & 140 & $(-)$ \\
\hline $30-40$ & $(37 \pm 3)$ & $55-65$ & $(6 \mathrm{I} \pm 3)$ & $35(-)$ & 130 & $(-)$ \\
\hline $40-50$ & $(47 \pm 3)$ & $80-85$ & $(83 \pm 2.5)$ & $45(-)$ & 140 & $(-)$ \\
\hline $30-35$ & $(32 \pm 2 \cdot 5)$ & $85-95$ & $(89 \pm 3.5)$ & $40 \quad(-)$ & 140 & $(-)$ \\
\hline $15-30$ & $(22 \pm 4 \cdot 6)$ & $90-95$ & $(91 \pm 2 \cdot 3)$ & $35(-)$ & 120 & $(-)$ \\
\hline $35-45$ & $(39 \pm 3.5)$ & $50-60$ & $(56 \pm 2 \cdot 7)$ & $35 \quad(-)$ & $130-140$ & $(135 \pm 2)$ \\
\hline $30-40$ & $\left(3^{8} \pm 3 \cdot 3\right)$ & $75-80$ & $(78 \pm 2 \cdot 2)$ & $(-)$ & 120 & $(-)$ \\
\hline $10-25$ & $(17 \pm 5)$ & I10-II5 & $(110 \pm I \cdot 6)$ & $40 \quad(-)$ & $130-140$ & $(135 \pm 3)$ \\
\hline $30-40$ & $(32 \pm 3 \cdot 3)$ & 90 & $(-)$ & $40(-)$ & 145 & $(-)$ \\
\hline $30-45$ & $(36 \pm 4 \cdot I)$ & $70-80$ & $(73 \pm 3 \cdot 3)$ & $35(-)$ & $130-140$ & $(137 \pm 4.5)$ \\
\hline
\end{tabular}

FI G.2 Bundle of His electrogram and standard lead II electrocardiogram (see text for explanation).

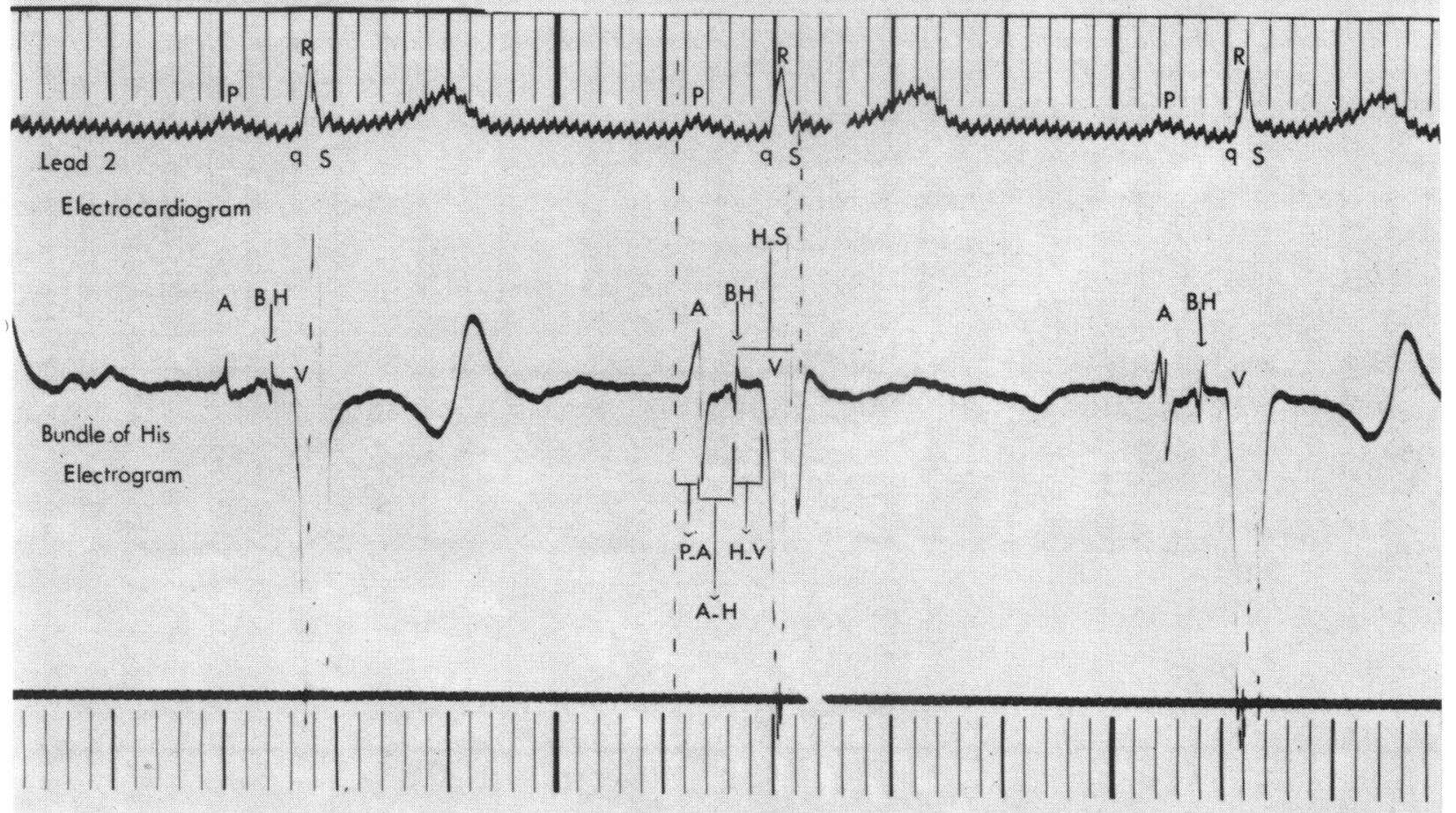




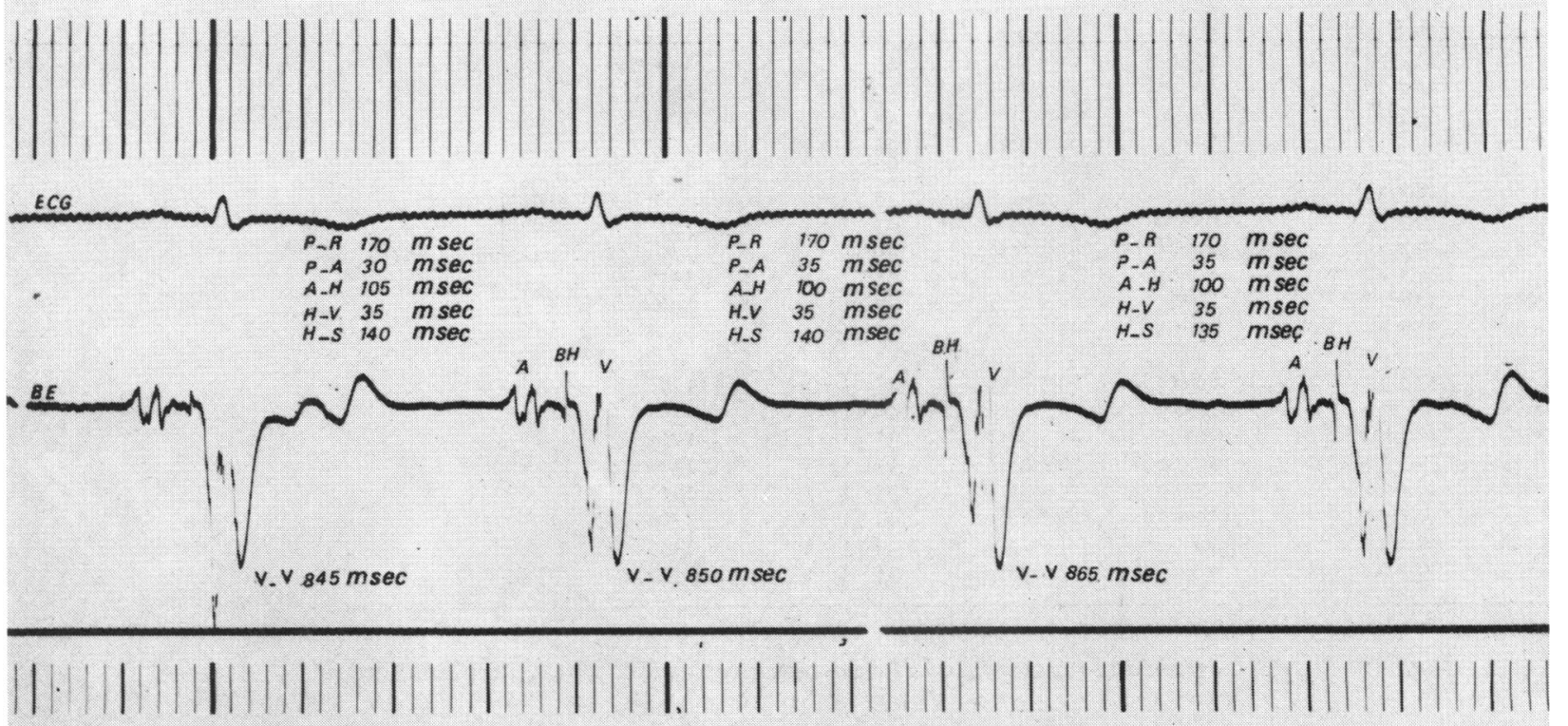

FIG. 3 Bundle of His electrogram; heart rate 69-70/min. Distance between 2 light vertical lines 40 msec.

FIG. 4 Bundle of His electrogram; heart rate 55-57/min. Distance between 2 light vertical lines 40 msec.

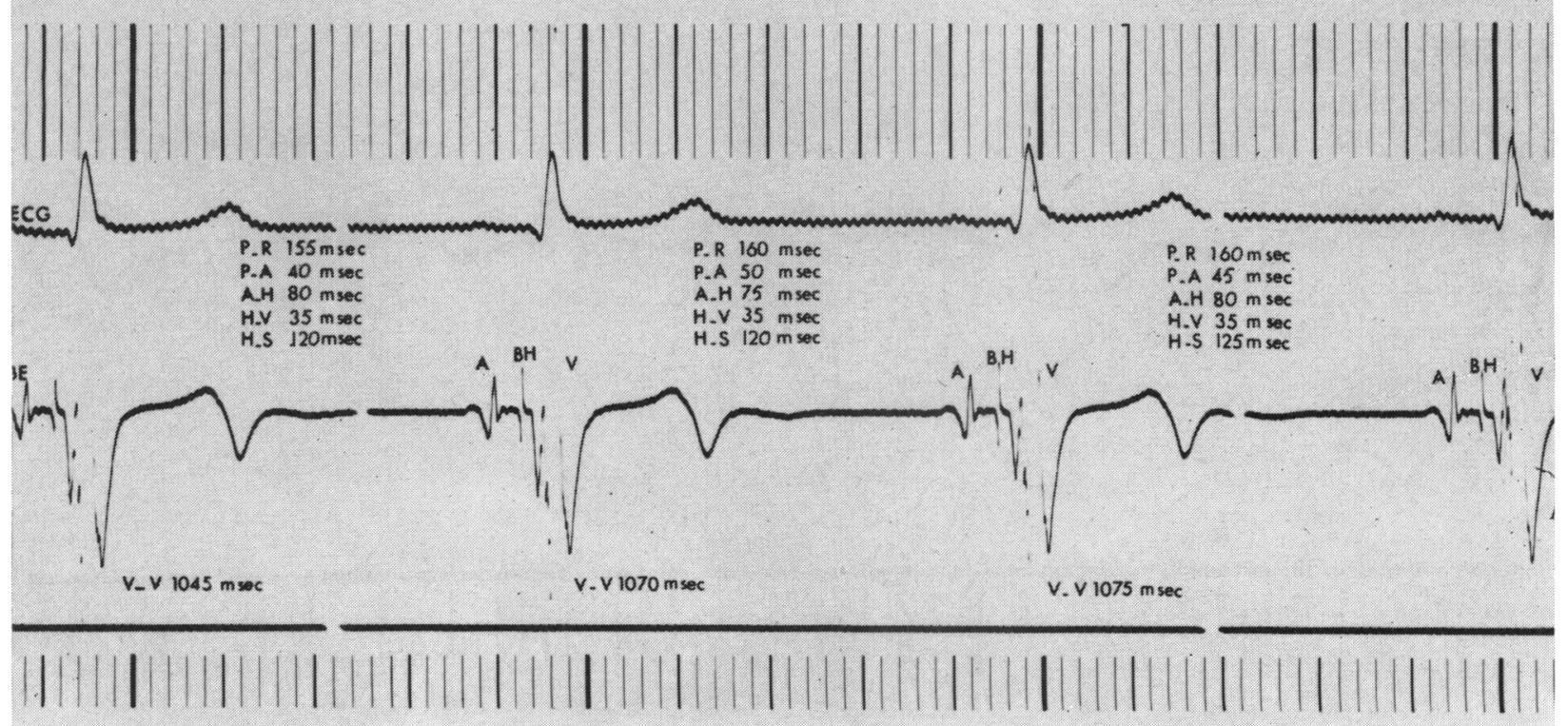




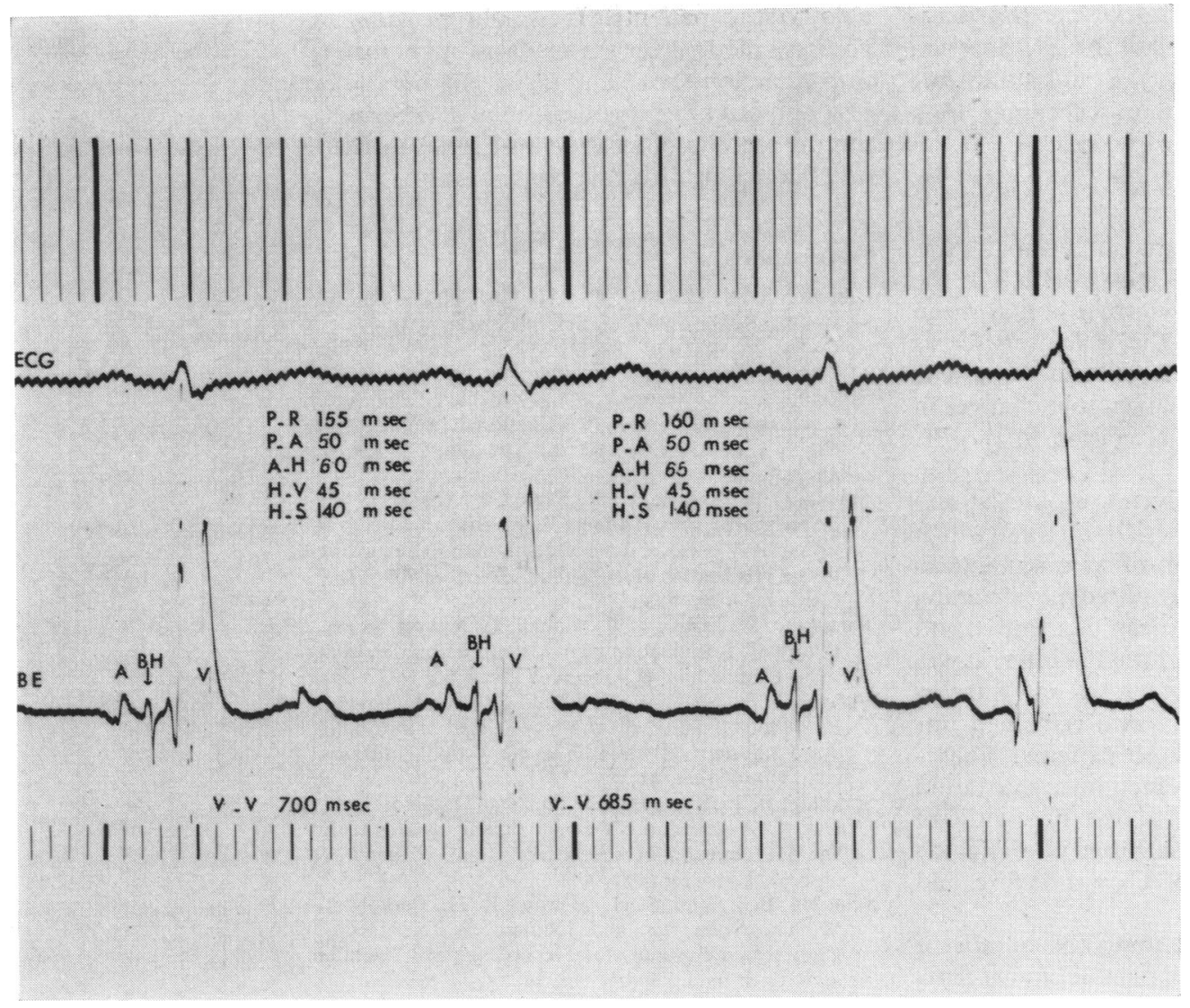

FIG. 5 Bundle of His electrogram; heart rate 85-87/min. Distance between 2 light vertical lines 40 msec.

FIG. 6 The heart rate and the PR and the $H V$ intervals before and after atropine $0.6 \mathrm{mg}$ intravenously in Case 2.

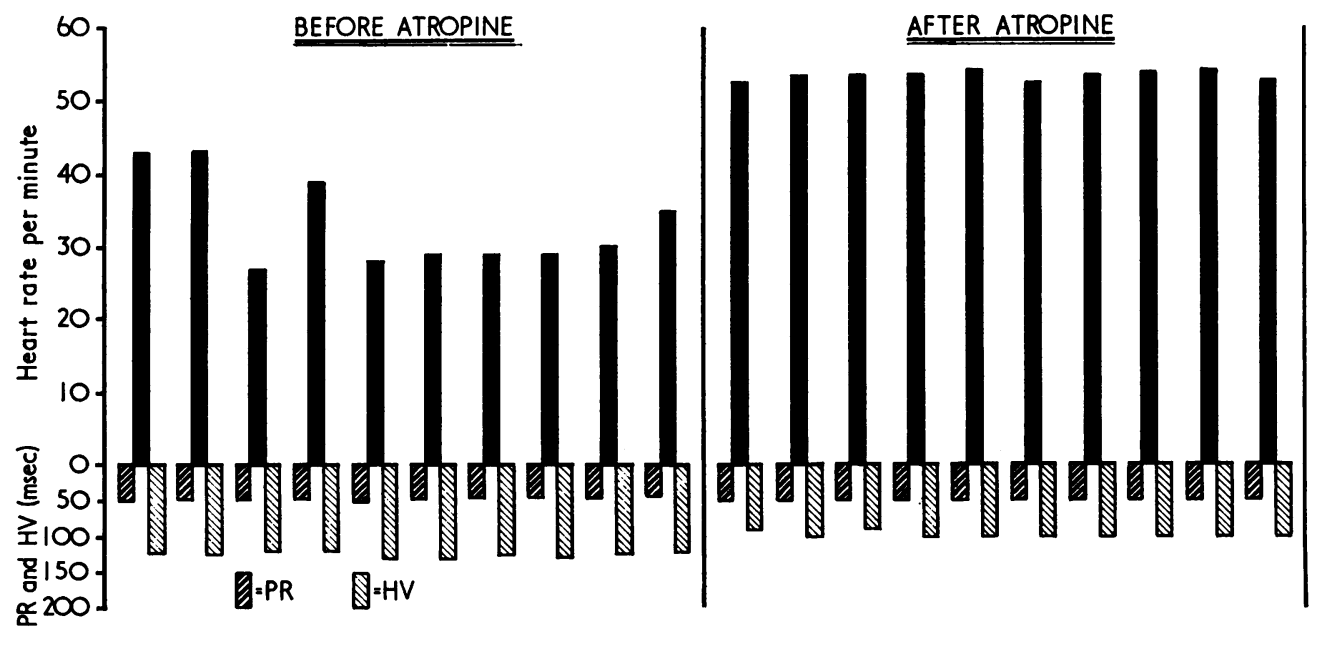


Narula et al. (1970a), namely, the BH duration was at least $15 \mathrm{msec}$ and the $\mathrm{HV}$ duration was at least $35 \mathrm{msec}$. Fig. 3, 4, and 5 illustrate bundle of His electrogram recordings in 3 patients with different heart rates.

\section{Discussion}

This study has shown that in normal sinus rhythm, in spite of the slight variation in the PR interval (within the normal limits, mean standard deviation 3.8 ), the $\mathrm{HV}$ interval was always constant for each subject. The His bundle electrogram has shown that changes in the PR intervals reflect alteration in the PA and $\mathrm{AH}$ intervals.

Cases 2 and 6 were given atropine $0.6 \mathrm{mg}$ intravenously to alter the $P R$ interval which was shortened by a mean of $22 \mathrm{msec}$ and 20 $\mathrm{msec}$, respectively. This resulted in shortening of the AH interval by a mean of I I msec and I4 msec, respectively, and the PA interval was shortened by a mean of $15 \mathrm{msec}$ and $8 \mathrm{msec}$, respectively. The HV interval remained unchanged at $45 \mathrm{msec}$ in both patients. Therefore, in normal sinus conduction any variation in the PR interval occurs above the bundle of His. Fig. 6 illustrates the heart rate and the $P R$ and HV intervals of Case 2 before and after atropine.

The technique of obtaining the bundle of His electrogram is simple, reliable, and accept- able to the patients. It should provide an accurate method for the analysis of anomalies in conduction above and below the bundle of His, and can be of practical value in determining the method of treatment of atrioventricular conduction disturbances.

\section{References}

Damato, S. N., Lau, S. H., Helfant, H., Stein, E., Patton, R. D., Scherlag, B. J., and Berkowitz, W. D. (1969). A study of heart block in man using His bundle recordings. Circulation, 39, 297.

Hoffman, B. F., Moore, E. N., Stuckey, J. H., and Cranefield, P. F. (1963). Functional properties of the A-V conduction system. Circulation Research, 13, 308.

Narula, O. S., Cohen, L. S., Samet, P., Lister, J. W., Scherlag, B., and Hildner, F. J. (1970a). Localization of $A-V$ conduction defects in man by recording of the His bundle electrogram. American fournal of Cardiology, 25, 228.

Narula, O. S., Lister, J. W., Cohen, L. S., and Samet, P. (1968). Localization of A-V conduction delays in man. Circulation, 38, Suppl. VI, 146.

Narula, O. S., Scherlag, B. J., and Samet, P. (1970b). Pervenous pacing of the specialized conducting system in man. His bundle and A-V nodal stimulation. Circulation, 41, 77.

Scherlag, B. J., Kosowsky, B. D., and Damato, A. N. (1967). A technique for ventricular pacing from the His bundle of the intact heart. Fournal of Applied Physiology, 22, 584 .

Scherlag, B. J., Lau, S. H., Helfant, R. H., Berkowitz, W. D., Stein, E., and Damato, A. N. (1969). Catheter technique for recording His bundle activity in man. Circulation, 39, 13. 